\title{
FORMAÇÃO DE OFICIAIS NA POLÍCIA MILITAR DO PARANÁ: UMA ANÁLISE EDUCACIONAL
}

\author{
Felipe Haleyson Ribeiro dos Santos ${ }^{\text {D1 } 1, ~ E d s o n ~ R o n a l d o ~ G u a r i d o ~ F i l h o ~ i D 2 ~}$ \\ Glauco Gomes de Menezes iD3
}

\section{Resumo}

O presente artigo visa analisar o processo de ensino dos cadetes que ingressam na Polícia Militar do Paraná com o objetivo de atuar na atividade-fim da organização. Para ingressar, os candidatos precisam participar do vestibular da Universidade Federal do Paraná, passar por vários tipos de provas específicas, para enfim ingressar no Curso de Formação de Oficiais que é realizado na Academia Policial Militar do Guatupê. O período de formação dura 04 anos, sendo que o último ano é dedicado ao período de estágio. Nesta pesquisa foram analisadas as matrizes curriculares no período de 1995 a 2019, o perfil dos instrutores no período de 2012 a 2020, o perfil dos candidatos e dos aprovados no período de 2005 a 2020. Também foram realizadas entrevistas narrativas com o comandante da Escola de Formação de Oficiais, e com os Aspirantes, que é nome dado após o cadete se formar para realizar o estágio. Além disso, foi realizada análise de vídeo com o objetivo de compreender a rotina do cadete durante o período do curso. Os resultados apontam que nos últimos anos ocorreram várias alterações no contexto da sociedade paraense que foram absorvidos pelos currículos escolares, os instrutores estão com graduações mais superiores, apesar da manutenção de preferência pela experiência profissional do instrutor. Evidenciou-se ainda que os candidatos possuem perfil diferente daqueles que ingressaram no começo do período analisado, em especial no que tange à formação acadêmica. Como limitações identificamos a necessidade de uma análise de conteúdo mais aprofundada das matrizes curriculares.

Palavras-chave: policial militar; formação; narrativas; ensino superior.

\section{TRAINING OF OFFICIALS IN THE MILITARY POLICE OF PARANÁ: AN EDUCATIONAL ANALYSIS}

\section{Abstract}

This article aims to analyze the teaching process of cadets who join the Paraná Military Police with the objective of acting in the organization's final activity. To

\footnotetext{
${ }^{1}$ Doutor em Gestão da Informação pela Universidade Federal do Paraná (UFPR). Mestre em Administração pela UFPR. Graduado em Administração pela Universidade Estadual de Londrina (UEL). Oficial da Polícia Militar do Paraná.

${ }^{2}$ Doutor em Administração pela Universidade Federal do Paraná (UFPR). Professor do Programa de Pós-Graduação em Gestão da Informação da UFPR e dos Programas de Pós-Graduação em Administração (PPGA/UP) e em Direito (PPGD/UP) da Universidade Positivo (UP). Bolsista Produtividade em Pesquisa Nível 2 do CNPq.

${ }^{3}$ Doutor e Pós-Doutor em Educação pela Universidade Federal do Paraná (UFPR). Mestre em Tecnologia pela Universidade Tecnológica Federal do Paraná (UTFPR). Professor Associado do Departamento de Administração Geral e Aplicada da UFPR.
}

Perspectivas em Diálogo, Naviraí, v. 09, n. 19, p. 262-281, jan./abr. 2022. 
enter, candidates must participate in the vestibular of the Federal University of Parana, go through various types of specific tests, to finally enter the Officer Training Course that is held at the Guatupê Military Police Academy. The training period lasts 04 years, and the last year is dedicated to the internship period. In this research were analyzed the curricular matrixes in the period of 1995 to 2019, the profile of the instructors in the period of 2012 to 2020, the profile of the candidates and those approved in the period of 2005 to 2020. In addition, narrative interviews were conducted with the Commander of the Officer Training School, and with the Aspirants, which is the name given after the cadet was trained to perform the internship. In addition, video analysis was conducted in order to understand the cadet's routine during the course. The results show that in recent years there have been several changes in the context of Pará society that have been absorbed by the school curricula, the instructors are with higher degrees, despite the maintenance of preference for the professional experience of the instructor. In addition, the candidates have a different profile from those who entered at the beginning of the analyzed period, especially with regard to academic training. As limitations, we have identified the need for a more indepth analysis of the content of the curriculum matrices.

Keywords: police; law enforcement; training; narratives; higher education.

\section{Introdução}

Para compor a base de dados do presente artigo, foi inicialmente solicitado formalmente à Academia Policial Militar do Guatupê (APMG) para que fornecesse informações acerca do Curso de Formação de Oficiais, uma vez que ela é responsável por gerenciar o processo de formação dos cadetes.

Para este artigo, não foram solicitados dados em determinado período, mas os dados mais antigos registrados e possíveis de serem disponibilizados. Apesar de se tratar de uma pesquisa descritiva (GIL, 2008), o foco não é analisar um período de tempo específico, mas a evolução e as alterações ocorridas no período.

Foi solicitado o envio da matriz curricular do CFO, sendo recebido um arquivo em PDF, e outro arquivo no formato .xlsx contendo dados de 1995 a 2018. Também foi solicitado e recebido a formação dos instrutores do CFO, sendo recebidos dados do período de 2012 a 2020.

Além disso, para analisar o processo de formação, foram utilizados dados da dissertação de mestrado de um dos autores, na qual foram realizadas entrevistas narrativas com o comandante da escola e os Aspirantes-a-Oficial (nome dado ao cadete depois de formado, mas em fase de estágio), e análise do vídeo que contém a rotina dos cadetes.

Por outro lado, também foi solicitado ao Núcleo de Concursos da UFPR para que encaminhasse os dados das respostas ao questionário socioeducacional que os candidatos ao CFO devem preencher no momento da inscrição para o vestibular. Foram disponibilizados dados separados por ano devido a alterações nas perguntas e nos itens dos questionários, no período de 2005 a 2020, bem 
como a informação se o candidato tinha sido aprovado ou não. Não foram solicitadas, muito menos disponibilizadas informações que pudessem identificar os candidatos.

Estes dados foram agrupados em uma única planilha, e neste processo as respostas foram agrupadas sob a questão que apresentava mesmo objetivo de resposta. Ao total foram identificadas 51 questões ao longo do período, e um total de 82.063 respondentes. Deste total, foi identificado que somente 1515 indivíduos foram aprovados. Mas, nem todos ingressaram na PMPR, pois em alguns anos depois do vestibular foram aplicadas provas específicas que podem ter diminuído ainda mais esta quantidade. Apesar disso, foi possível comparar os dois perfis.

Para a análise das entrevistas, o método narrativo aparenta ser o mais adequado por compreender as experiências dos indivíduos (CUNLIFFE; COUPLAND, 2012; RIESSMAN, 2007), e dos demais dados foram utilizadas planilhas excel para agrupar os dados, e produção de resultados com apoio de tabelas dinâmicas.

\section{Formação do Policial Militar}

Pereira Basilio (2010) realizou uma análise aprofundada sobre o processo de formação do policial militar, inclusive analisando os programas das disciplinas e a estrutura curricular do curso. Mesmo sendo voltado para o curso de formação de Soldados (CFSd), por meio deste artigo podemos compreender que o ingresso decorre de um processo seletivo, seguido de um intenso período de treinamento, e em alguns Estados esse processo ocorre de forma descentralizada.

O autor ainda aponta que o CFSd da Polícia Militar do Estado do Rio de Janeiro, possui alta carga horária (1160 h/a) concentrada em curto período (32 semanas). O programa é formado por várias disciplinas de curto período duração.

Isso aponta a complexidade da atividade policial, pois a quantidade de disciplinas representa o volume de informações que precisam ser transmitidas ao policial militar para deixa-lo pronto para a atividade policial.

Por outro lado, Santos (2016) realizou a análise do Curso de Formação de Oficiais, mas sob a perspectiva das experiências vividas pelos indivíduos na construção de sua identidade profissional e concluiu que a identidade profissional começa a ser construída antes mesmo do indivíduo ingressar na organização. Além disso, identificou que durante o período de formação existem duas lógicas institucionais que atuam neste processo: A lógica Militar, que orienta as práticas adotadas durante a vivência dos cadetes na Academia Policial Militar do Guatupê (APMG) e uma Lógica Policial que orienta o conteúdo de ensino que é transmitido ao cadete quando este se encontra em sala de aula.

Neste mesmo objetivo, mas analisando a Polícia Rodoviária Federal, Morais e Paula (2010) analisaram a construção da identidade profissional, mas sob a perspectiva da constituição da subjetividade e identificaram que o processo 
de formação não é somente uma qualificação da força de trabalho, mas também os indivíduos são submetidos à ideologia dominante. Aqui ele também aponta que o curso de formação é um processo de socialização do indivíduo (VAN MAANEN, 1978).

Ribeiro, Cruz e Batitucci (2005) aponta que organizações policiais podem ser consideradas instituições totais (GOFFMAN, 1961), e classificadas como tais é possível observar que as organizações policiais realizam a socialização com o objetivo de transformar o indivíduo em um policial "que seja capaz de obedecer, de forma inquestionável, às determinações e aos propósitos organizacionais, garantindo 'teoricamente', a eficiência na produção da segurança pública" (RIBEIRO; CRUZ; BATITUCCI, 2005, p. 298).

Além disso, ele também analisa o perfil do ingressante seja para o CFO, seja para o CFSd. E por meio de um survey avalia três dimensões da vida do indivíduo: Trabalho, Lazer e Residência. Ele conclui que os mecanismos de socialização, controle e motivação se revelam não tão suficientes para promover a obediência dos subordinados, o que demanda a revisão de tais mecanismos.

Manning (2003) analisa a evolução da Polícia americana e identificou que ao longo do tempo ocorreu uma intensa profissionalização do serviço policial, em especial em decorrência do avanço tecnológico recente. Este processo de profissionalização faz com que o policial seja mais técnico, tornando mais informal sua atividade e seu comprometimento com a organização.

Ao analisar as organizações policiais nos EUA, Manning (2008, p. 25, tradução nossa) aponta que os "valores centrais de organizações policiais são compostos de ideias medievais como dever, honra, lealdade pessoal aos superiores, e obediência que que são parcialmente reveladas nas práticas". Estes valores não podem ser encaradas aqui pelo víeis negativo de que a organização não se renova, mas pelo contrário, estes valores são os responsáveis por permitir que este tipo de organização cumpra seu papel.

Esta dicotomia entre os valores medievais e a profissionalização da atividade policial pode ser um dos motivos pelos quais os mecanismos de socialização, controle e motivação mencionados por Ribeiro, Cruz e Batitucci (2005) sejam necessários ser revistos.

Santos (2016) também identificou durante o período de formação, ocorre um intenso processo de Sensemaking devido aos gatilhos que são acionados tanto pela coordenação do CFO quanto pela interação com os demais cadetes da Escola. Estes gatilhos lidam com esta dicotomia profissionalização-valores, pois acionam simultaneamente elementos da lógica militar e da lógica policial no convívio dos cadetes, conforme podemos visualizar na narrativa de Stive (SANTOS, 2016)

Diante disso, podemos concluir que o processo de formação de policiais militares não é o mesmo que ocorre em outras Instituições de Ensino Superior, pois no caso de organizações policiais a formação decorre de um processo mais associado à socialização e transmissão de experiência. 


\section{Metodologia}

Para compor a base de dados do presente artigo, foi inicialmente solicitado formalmente à Academia Policial Militar do Guatupê (APMG) para que fornecesse informações acerca do Curso de Formação de Oficiais, uma vez que ela é responsável por gerenciar o processo de formação dos cadetes.

Para este artigo, não foram solicitados dados em determinado período, mas os dados mais antigos registrados e possíveis de serem disponibilizados. Apesar de se tratar de uma pesquisa descritiva (GIL, 2008), o foco não é analisar um período de tempo específico, mas a evolução e as alterações ocorridas no período.

Foi solicitado o envio da matriz curricular do CFO, sendo recebido um arquivo em PDF, e outro arquivo no formato .xIsx contendo dados de 1995 a 2018. Também foi solicitado e recebido a formação dos instrutores do CFO, sendo recebidos dados do período de 2012 a 2020.

Além disso, para analisar o processo de formação, foram utilizados dados da dissertação de mestrado de um dos autores, na qual foram realizadas entrevistas narrativas com o comandante da escola e os Aspirantes-a-Oficial (nome dado ao cadete depois de formado, mas em fase de estágio), e análise do vídeo que contém a rotina dos cadetes.

Por outro lado, também foi solicitado ao Núcleo de Concursos da UFPR para que encaminhasse os dados das respostas ao questionário socioeducacional que os candidatos ao CFO devem preencher no momento da inscrição para o vestibular. Foram disponibilizados dados separados por ano devido a alterações nas perguntas e nos itens dos questionários, no período de 2005 a 2020, bem como a informação se o candidato tinha sido aprovado ou não. Não foram solicitadas, muito menos disponibilizadas informações que pudessem identificar os candidatos.

Estes dados foram agrupados em uma única planilha, e neste processo as respostas foram agrupadas sob a questão que apresentava mesmo objetivo de resposta. Ao total foram identificadas 51 questões ao longo do período, e um total de 82.063 respondentes. Deste total, foi identificado que somente 1515 indivíduos foram aprovados. Mas, nem todos ingressaram na PMPR, pois em alguns anos depois do vestibular foram aplicadas provas específicas que podem ter diminuído ainda mais esta quantidade. Apesar disso, foi possível comparar os dois perfis.

Para a análise das entrevistas, o método narrativo aparenta ser o mais adequado por compreender as experiências dos indivíduos (CUNLIFFE; COUPLAND, 2012; RIESSMAN, 2007), e dos demais dados foram utilizadas planilhas excel para agrupar os dados, e produção de resultados com apoio de tabelas dinâmicas. 


\section{A Estrutura de Ensino na PMPR}

Na Polícia Militar do Estado do Paraná, a Academia Militar do Guatupê (APMG) é responsável por gerenciar os processos de ensino, ou seja, possui por atribuição a organização e coordenação de cursos realizados na Corporação.

Os Cursos de Formação de Soldados pode ser realizado de forma descentralizada, tanto ocorrendo na APMG quanto em unidades operacionais que possuam estrutura para realizar tais cursos.

Já o Curso de Formação de Oficiais (CFO) é realizado exclusivamente na APMG, e é reconhecido como curso de nível superior.

Conforme contido em APMG (2020), é possível identificar que a semelhança com cursos de outras Instituições de Ensino Superior se inicia pelo fato de que o curso é reconhecido como equivalente a curso superior, o que demanda uma forma de ensino diferenciada quando comparado a um curso profissionalizante por exemplo.

Para melhor visualizar estas diferenças, foi solicitado formalmente à APMG para que encaminhasse o currículo do CFO desde o registro mais antigo disponível pela via digital. Diante da solicitação, foram encaminhadas as matrizes curriculares contendo as disciplinas por turma ( $1^{0}$ ano, $2^{\circ}$ ano e $3^{\circ}$ ano), por ano (1995 - 2018), o que gerou um documento contendo 90 folhas para análise.

O primeiro passo foi listar as disciplinas por ano, e por carga horária. Porém, neste caso existem dois caminhos que podem ser adotados. $O$ primeiro seria analisar a oferta da disciplina naquele ano ou analisar por turma. Como nosso foco não é analisar o percurso formativo do cadete, mas sim as disciplinas em si, foi adotado o primeiro método para classificação das disciplinas.

Inicialmente, não foi realizado nenhum filtro nas disciplinas, mesmo que ela tivesse mudado de nome (por exemplo, Trabalho de Comando até 2012, e Trabalho de Comando e Estado Maior de 2013 a 2018). Apesar de parecer óbvio que ambas tratam do mesmo assunto, o objetivo inicial era somente tabular as disciplinas, sem considerar qualquer tipo de análise.

Outro ponto que merece destaque, é o fato de que no ano de 2016 foi expedida Portaria do Comando-Geral da PMPR definindo a Matriz Curricular do CFO. Nesta Portaria, há a definição de que as alterações nas matrizes somente podem ser realizadas mediante a instauração de uma comissão e que para realizar a sua alteração, ou seja, antes deste período a alteração ficava a critério do Comandante da APMG. Isso pode explicar porque há tanta alteração nas disciplinas do período, uma vez que os Comandantes da APMG são definidos entre os Oficiais do último Posto da Corporação, Coronel, o qual já possui avançado tempo de serviço. Portanto, resulta em rodízio de comando pela transferência para a Reserva Remunerada. Alteração de Comando com poder de alteração na matriz curricular, pode ser uma das explicações para a variedade encontrada nesta pesquisa. 
Desta análise inicial, foi identificado que no período de 23 anos, o CFO teve no total 308 disciplinas, e a sua carga horária total oscilou conforme contido no Gráfico 1.

Gráfico 1 - Carga Horária CFO PMPR

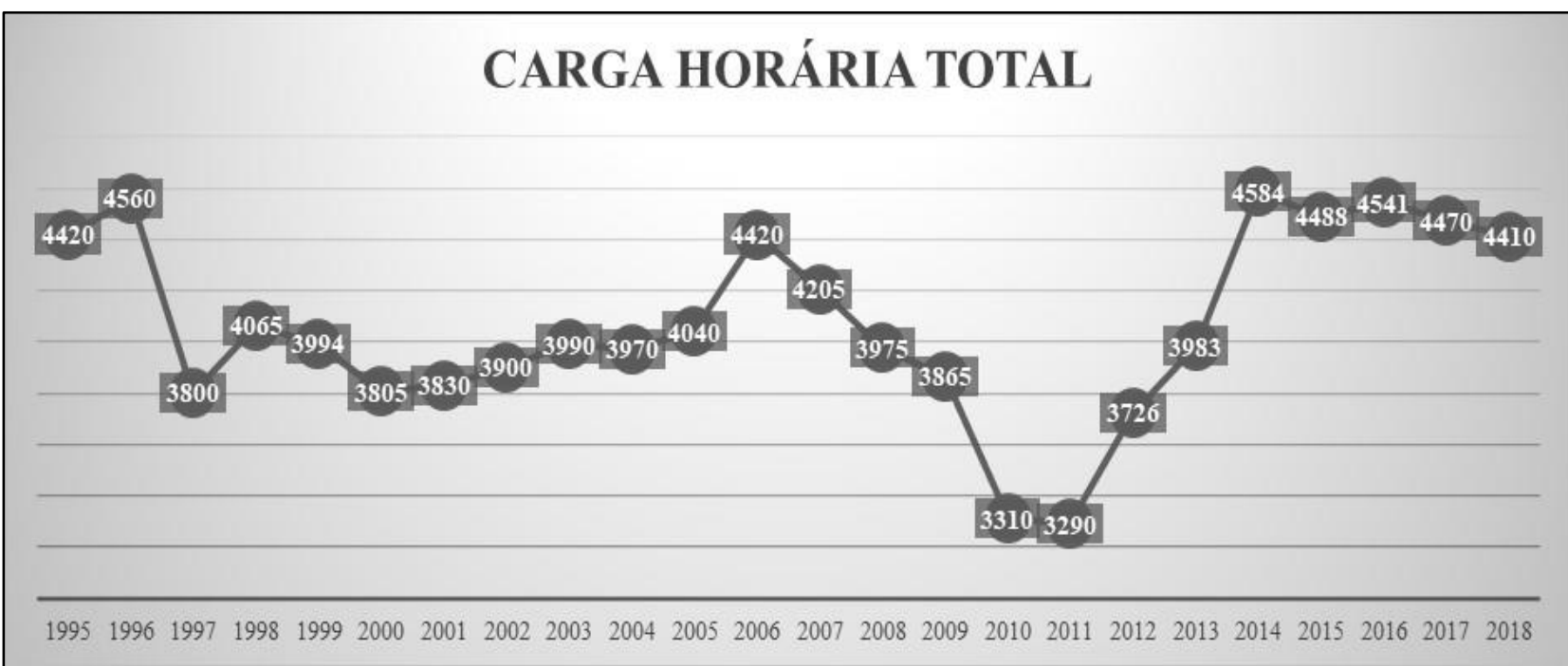

Fonte: os autores (2020).

Assim, podemos visualizar que o valor mínimo atingido pela carga horária foi no ano de 2011, $3290 \mathrm{~h} / \mathrm{a}$, e o valor máximo ocorreu o ano de $2014 \mathrm{com}$ $4584 \mathrm{~h} / \mathrm{a}$, o que representa uma oscilação de $1294 \mathrm{~h} / \mathrm{a}$, e ainda mais quando consideramos o curto espaço de tempo que isso ocorreu. Contudo, é possível visualizar que não foi uma mudança brusca, o que pode indicar a intenção do administrador em diminuir a carga horária, para em seguida mudar esta mesma carga horária em decorrência de algum outro fator que não pode ser identificado por esta pesquisa.

Após isso, as disciplinas foram agrupadas de acordo com o tema principal que se referem e agrupadas de acordo com as seguintes categorias: Administração, Coordenação, Direito, Direito policial, Direito atividade policial, Base acadêmica, Línguas, Tecnologias da Informação e Comunicação (TIC), Pesquisa, Educação física, Ensino, Militar, Atividade BM, Base policial, Técnicas de policiamento e Atividade policial.

Ao somar as cargas horárias destas disciplinas identificamos a evolução constante no

Gráfico 2. Por meio dele, podemos identificar que o grande salto ocorrido no ano de 2011 foi em decorrência do aumento na quantidade de horas disponível para a Coordenação.

A análise deste grupo permite concluir identificar que Educação Física é uma constante na formação do policial militar, pois apesar da oscilação ao longo do tempo, em 1995 foram disponibilizadas $740 \mathrm{~h} / \mathrm{a}$ ao passo que em 2018 foram 720 h/a, o que indica a estabilidade desta disciplina. 
Quando fazemos um novo agrupamento dos grupos acima identificados podemos elaborar a seguinte divisão percentual das disciplinas. Para este cálculo, identificamos a média de h/a por grupo temático, e calculamos o percentual sobre a média da carga horária total, ambos considerando o período 1995 a 2018. A soma dos valores não soma $100 \%$ por se tratar de valores médios.

Tabela 1 - Percentual por grupo temático

\begin{tabular}{|c|c|}
\hline GRUPO TEMÁTICO & PERCENTUAL \\
\hline POLICIAL & $33,96 \%$ \\
\hline DIREITO & $17,05 \%$ \\
\hline EDUCAÇÃO FÍSICA & $16,12 \%$ \\
\hline ADMINISTRAÇÃO & $7,23 \%$ \\
\hline OUTRAS DISCIPLINAS & $6,82 \%$ \\
\hline MILITAR & $4,64 \%$ \\
\hline TIC & $2,39 \%$ \\
\hline PESQUISA & $1,68 \%$ \\
\hline
\end{tabular}

Fonte: os autores (2018).

Assim, podemos concluir que há uma preocupação em formar o oficial com carga de conhecimento da atividade policial, mas o grupo de disciplina de Direito ocupa grande quantidade da carga horária. Outro ponto interessante aqui é que o grupo de disciplinas da Administração está reduzida quando comparada com as demais.

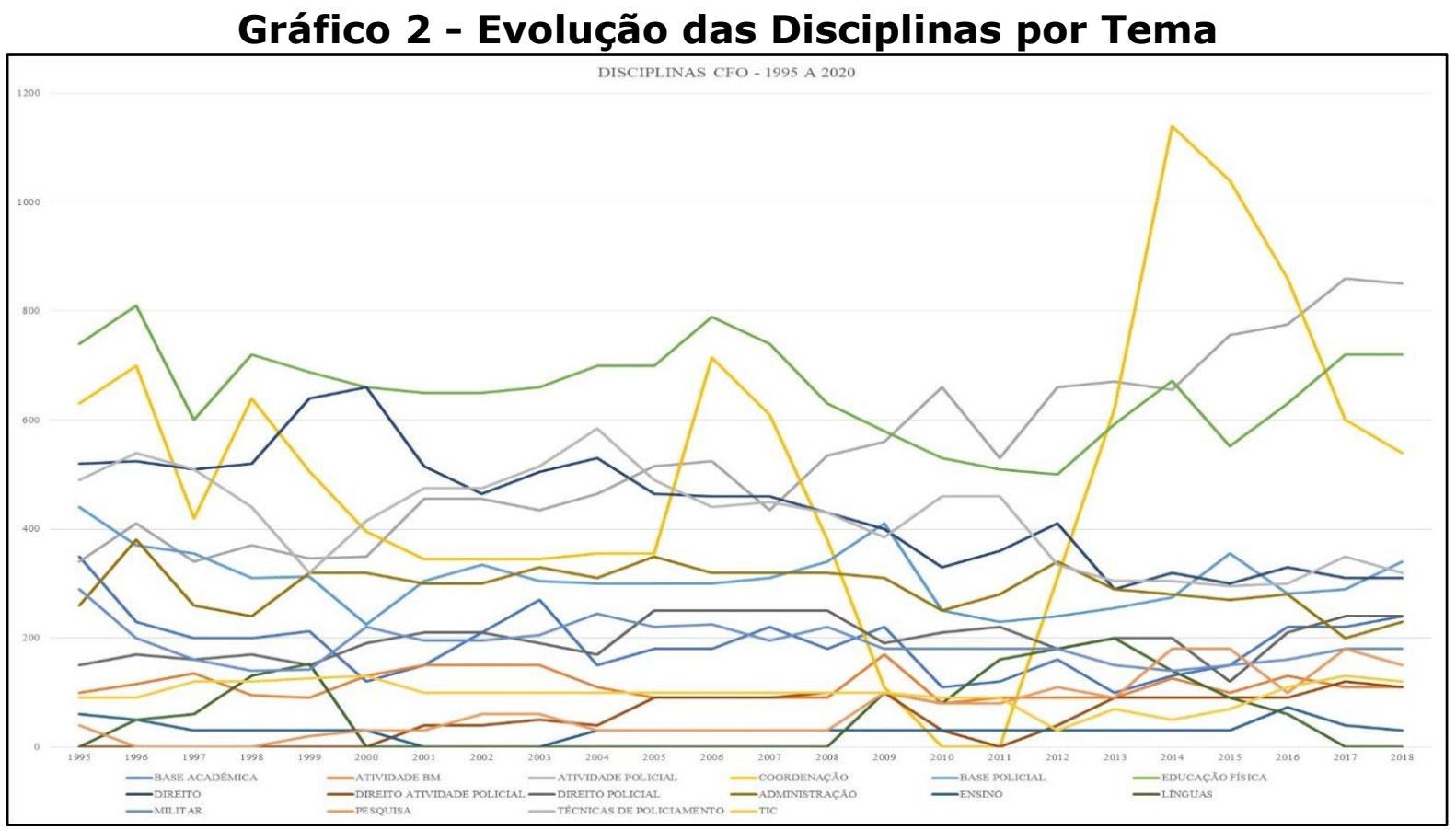

Fonte: os autores (2020). 
Quando observamos a linha temporal do grupo de disciplinas, podemos observar que o grupo de disciplinas policiais é o mais elevado do grupo, e é possível observar que houve bastante oscilação no período, mas retornou próximo dos valores que eram realizados em 1995.

Por outro lado, o Gráfico 3 apresenta o quadro completo da evolução das disciplinas, no qual é possível visualizar que apesar de na média, Educação Física e Direito apresentam a maior concorrência entre si, sendo que no último ano, Educação Física se sobrepôs.

\section{Gráfico 3 - Evolução por Grupo de Disciplinas}

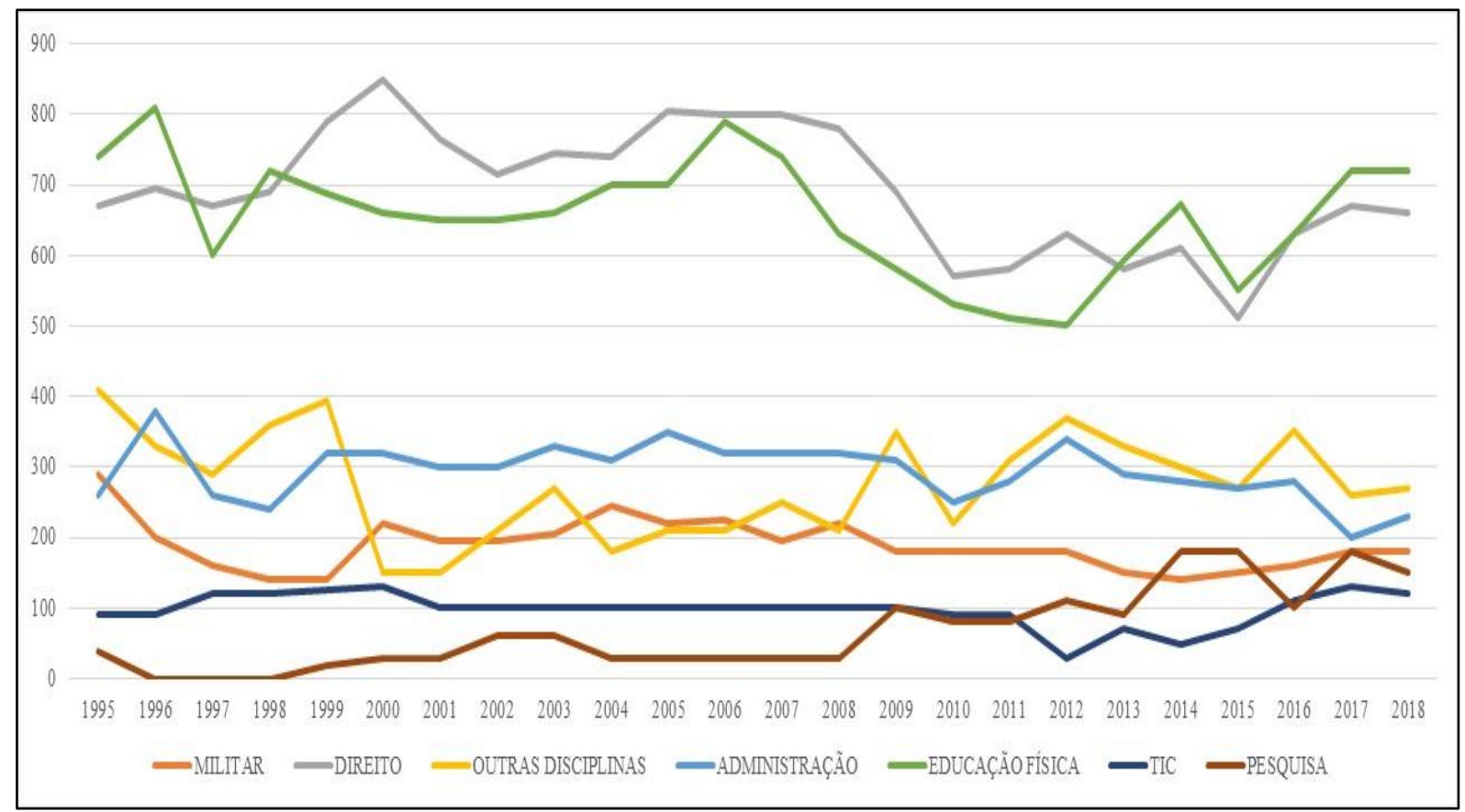

Fonte: os autores (2020).

Além disso, podemos identificar as disciplinas de Administração tiveram queda ao longo do tempo, sendo ela essencial para ensinar o Oficial como administrar a Corporação. Um dos motivos que impulsionam tal queda decorre do fato de que incialmente o formado não atua diretamente na administração.

As disciplinas militares foram colocadas à parte, pois representam aquelas de transferência de conhecimento relativo à cultura, princípios e valores organizacionais. É possível também visualizar que outras disciplinas tiveram bastante oscilação no período, o que indica a instabilidade de decisão da organização quanto a quais disciplinas seriam adequadas, uma vez que aqui foram agrupadas aquelas disciplinas com ofertas em curtos períodos, ou que são de base acadêmica do ensino superior como por exemplo Sociologia, Antropologia, Filosofia, etc.

Por fim, convém destacar os dois grupos que se encontram em ascensão, TIC e pesquisa. A primeira decorre da necessidade de adaptação da PMPR às inovações tecnológicas, ao passo que a segunda representa a inovação dentro 
dos planos de ensino com a inclusão do Trabalho de Conclusão de Curso e disciplinas a ele atreladas como Metodologia Científica.

Esta análise permite observar que ao longo do tempo houve uma constante alteração nas disciplinas do CFO. Quando analisamos as 308 disciplinas identificamos que elas foram se adaptando ao longo do tempo, em especial quando consideramos a implantação da pesquisa no currículo daquela organização, as disciplinas jurídicas que tiveram de ser aumentadas, e o aumento nas disciplinas de Tecnologia. Isso demonstra que além de um processo de socialização, a formação é um processo por meio do qual o contexto organizacional alcança o indivíduo.

\section{As experiências no processo formativo}

Para analisar o processo formativo, foram realizados os seguintes métodos: análise de vídeo; entrevista narrativa com o Comandante da Escola de Formação de Oficiais; e entrevista narrativa com 03 Aspirantes a Oficial que se formaram no ano de 2013 e 2014.

Os dados foram coletados para fins da dissertação de um dos autores (SANTOS, 2016), e estão sendo analisados sob a perspectiva do ensino deste artigo, por isso que o tempo de entrevista pode ser um pouco antigo. Mas, é também preciso levar em consideração que esta pesquisa apresenta um caráter longitudinal, visando analisar os processos ocorridos no período de formação, e como os dados da dissertação foram coletados dentro do período das análises deste artigo, apresentam coerência e confiabilidade. Nos anexos da dissertação podem ser encontrados os dados utilizados na pesquisa.

O Vídeo (2006) analisado foi uma reportagem realizada por um televisão paranaense no qual retrata a rotina do Cadete no ano de 2006. Cunliffe e Coupland (2012, p. 70 tradução nossa) apontam que "documentários são particulares construções de eventos, eles mostram protocolos sociais de conhecimento e práticas institucionalizadas pela presença de um senso de realidade", então por meio da análise deste vídeo é possível identificar a rotina que os cadetes foram submetidos.

Para a análise, foi seguida a orientação de Rose (2015) na qual o áudio e imagens são transcritos.

A análise do vídeo resultou no contido no Erro! Fonte de referência não encontrada.. De acordo com o método, a dimensão visual apresenta os aspectos que estão sendo mostrados no vídeo, e a Dimensão verbal apresenta os sons e narrativas que estão contidas no vídeo.

Assim, foi possível identificar que o cadete possui uma rotina marcada por horários, a presença da Lógica Militar é bastante presente seja pelas formaturas e desfiles, seja pela postura dos cadetes.

Neste vídeo, também é possível perceber a dualidade das duas lógicas de formação. O caráter militar representado pelas práticas fora da sala de aula: arrumar camas, horários definidos, continências, formaturas militares etc. E por 
outro lado, na execução das disciplinas é possível visualizar a lógica policial pelo ensino de técnicas policiais e uso de esforço físico em atividade de simulação de obstáculos.

A entrevista narrativa com o Comandante da Escola foi realizada em setembro de 2015 e teve $41 \mathrm{~min} 47 \mathrm{seg}$ de duração, sendo devidamente transcrita para a análise. Para esta entrevista foi adotada o método de entrevista narrativa, na qual "a atenção muda para os detalhes - como e por que um evento em particular é relatado, talvez, ou o que o narrador compreende ao desenvolver a história daquele jeito, bem como os efeitos no leitor ou no ouvinte" (RIESSMAN, 2007, p. 12 tradução nossa).

$\mathrm{Na}$ entrevista com o Comandante da Escola foram identificados os mesmos elementos apontados na análise do vídeo, como por exemplo a rotina dos cadetes ser bastante preenchida com atividades. Além disso, existe a figura do Coordenador que além de cuidar das questões administrativas é responsável por atuar como Sensegiver (GIOIA; CHITTIPEDDI, 1991) dos cadetes.

Weick (1995) aponta que Sensemaking ocorre no meio organizacional por meio de gatilhos, e que a partir de tais gatilhos o indivíduo tenta conceder sentido àquilo que ele percebe. Entretanto, no meio organizacional isto não ocorre de modo independente. O processo de Sensegiving descrito por Gioia e Chittipeddi (1991) aponta que o Sensemaking pode ser orientado por ações organizacionais.

Ou seja, no processo de formação do cadete, o indivíduo é imerso no contexto organizacional, depara-se com inúmeros gatilhos e busca dar sentido à tudo aquilo. Cada indivíduo possui um modo de interpretar o meio, mas as organizações comumente esperam um comportamento padronizado, ainda mais quando são comparadas com instituições totais (GOFFMAN, 1961). A fim de padronizar este comportamento, a figura do Coordenador de Curso no contexto do CFO é atuar como este Sensegiver, orientando os cadetes sobre a forma correta de agir. Algo que hoje pode ser definido como mentoria ou coaching.

Nas entrevistas narrativas com os Aspirantes, foi possível identificar que os conflitos entre as turmas também influenciam no processo de formação, em especial entre as turmas de segundo e terceiro ano. O primeiro ano é turma de ingresso, ainda não tem conhecimento do contexto organizacional. O segundo ano é turma que já possui certo conhecimento, mas não possui poder na escola, o que de acordo com o Comandante da Escola estaria vinculada à responsabilidade por determinadas atribuições. Já o terceiro ano, veteranos de Curso são responsáveis por coordenar inúmeras tarefas e atribuir tarefas para as demais turmas.

Outro elemento essencial aqui são as narrativas. Tanto no vídeo, na entrevista com o Comandante da Escola e com os Aspirantes, identificamos que as experiências vividas serviram para que os cadetes pudessem se formar, e serviram para que eles pudessem ser formados tanto pela coordenação da escola, quando pelas turmas superiores. 
Desta análise, podemos concluir que em somatória à influência contextual alcançada por meio das matrizes curriculares, identificamos que as narrativas representam o meio pelo qual a organização forma os seus indivíduos.

As narrativas atuam em sala de aula com os instrutores repassando a sua experiência, de acordo com a matriz curricular que define os assuntos relevantes contextualmente para a organização. E fora da sala de aula, nas interações e atividades acadêmicas as narrativas decorrem de processos imbricados de Sensemaking e Sensegiving, entre a coordenação, turmas e indivíduos.

\section{O Perfil dos Instrutores}

A fim de triangular a análise foi também realizada a análise do perfil dos instrutores com o objetivo de identificar possíveis diferenças que podem impactar na formação do oficial da PMPR (CRESWELL, 2007; STAKE, 2009). Assim, foi solicitado à Academia Policial Militar do Guatupê que encaminhasse os dados disponíveis de instrutores do Curso de Formação de Oficiais.

$\mathrm{O}$ arquivo recebido foi uma planilha excel, contendo um total de 975 linhas de instrutores da APMG no período de 2012 a 2020, ao realizar o agrupamento foi identificado que no período foram 340 instrutores que atuaram na instituição. A formação acadêmica dos instrutores pode ser visualizada na Tabela 2, na qual podemos identificar que nos últimos anos houve um aumento considerável no número de doutores e mestres atuando nesta instituição de ensino.

Tabela 2 - Formação Acadêmica dos Instrutores APMG

\begin{tabular}{|c|c|c|c|c|c|c|c|c|c|c|}
\hline & $\mathbf{2 0 1 2}$ & $\mathbf{2 0 1 3}$ & $\mathbf{2 0 1 4}$ & $\mathbf{2 0 1 5}$ & $\mathbf{2 0 1 6}$ & $\mathbf{2 0 1 7}$ & $\mathbf{2 0 1 8}$ & $\mathbf{2 0 1 9}$ & $\mathbf{2 0 2 0}$ & Total Geral \\
\hline Doutorado & 8 & 7 & 9 & 4 & 2 & 6 & 6 & 11 & 1 & 54 \\
\hline Mestrado & 35 & 38 & 36 & 33 & 27 & 37 & 37 & 45 & 9 & 297 \\
\hline Especialização & 59 & 87 & 56 & 50 & 38 & 67 & 56 & 83 & 19 & 515 \\
\hline Graduação & 6 & 23 & 14 & 17 & 12 & 12 & 10 & 10 & 2 & 106 \\
\hline Não Informado & 1 & 1 & 1 & & & & & & & 3 \\
\hline Total Geral & 109 & 156 & 116 & 104 & 79 & 122 & 109 & 149 & 31 & 975 \\
\hline
\end{tabular}

Fonte: os autores (2020).

Por outro lado, quando se observa a idade dos docentes, conclui-se que a idade média é de 37,25 anos de idade. Para este cálculo, foi considerado somente o ano de nascimento, e o ano que o instrutor lecionou a disciplina.

Por outro lado, ao analisarmos o tempo de serviço, podemos identificar que o tempo de serviço médio dos instrutores é de 16,52 anos de serviço.

Por fim, é possível visualizar o contido na Tabela 3 a distribuição de instrutores de acordo com o Posto e Graduação. Nesta tabela, conclui-se que há uma preponderância por Capitães e Tenentes como instrutores, e a questão 
disciplinar também aparece de forma preponderante dada a baixa quantidade de praças (Sargentos e Cabos) que atuaram como instrutores.

\section{Tabela 3 - Posto/Graduação dos Instrutores}

\begin{tabular}{|c|c|}
\hline POSTO/GRADUAÇÃO & QUANTIDADE \\
\hline Coronel & 9 \\
\hline Tenente-Coronel & 41 \\
\hline Major & 128 \\
\hline Capitão & 344 \\
\hline 10 Tenente & 364 \\
\hline $2^{\circ}$ Tenente & 81 \\
\hline Aspirante Oficial & 3 \\
\hline 20 Sargento & 1 \\
\hline Cabo & 3 \\
\hline Civil & 1 \\
\hline Total Geral & 975 \\
\hline
\end{tabular}

Fonte: os autores (2020).

Ao analisar a Tabela 2, idade média, tempo de serviço e Tabela 3 é possível concluir que há preferência por instrutores que atuam na corporação, e que tais instrutores possuem experiência considerável nas atividades da Corporação. Ainda mais quando se considera a divisão entre níveis administrativos (Estratégico, Tático e Operacional) aplicado aos postos do Oficiais, identifica-se a preponderância de instrutores do nível tático da carreira, apontando que a Academia Policial Militar do Guatupê tem por foco da primeira formação a atuação neste nível da Corporação.

Outro ponto que merece destaque é que a formação acadêmica destes policiais, pois apesar de tempo de serviço médio de 16 anos, e idade média de 37 anos, a escolaridade dos instrutores ainda se encontra limitada ao nível de especialização, e por outro lado há indícios de que o nível dos instrutores tem se aprimorado recentemente.

Existem dois motivos que podem ajudar a explicar isto. No ano de 2015 houve uma mudança na legislação para a promoção de Oficiais (PARANÁ, 1969) que incluiu a contagem de pontos de Doutorado e Mestrado para fins de promoção, o que antes não podia ser realizada.

Por outro lado, a APMG se vinculou à Universidade Estadual do Paraná (UNESPAR) no ano de 2013 (APMG, 2020). Apesar do Curso de Formação de Oficiais ser reconhecido como equivalente a nível superior desde 1982, a instituição em si não possuía reconhecimento como instituição de ensino superior. A partir de tal reconhecimento, a APMG se tornou campus da UNESPAR, e com isso ficou incorporou as regras de tal universidade, dentre elas a busca pela pesquisa, e instrutores de alto nível, o que por consequência pode ter feito a APMG buscar instrutores mais graduados. 


\section{Perfil dos Candidatos ao CFO}

Para a análise do perfil dos candidatos, todas as 48 tabelas que foram enviadas pelo Núcleo de Concursos da UFPR foram agrupadas em uma única tabela. Ao total foi identificado que no período de 2005 a 2020, é possível identificar que dos 82.062 candidatos, apenas 1697 foram aprovados, ou seja apenas $2,06 \%$ de taxa de aprovação. Destes candidatos, cerca de $32 \%$ são do sexo feminino, sendo possível observar que ao longo dos anos o percentual de pessoas do sexo feminino aumentou de $2 \%$ para $28 \%$. Por fim, cerca de $17 \%$ foram candidatos ao curso de Bombeiro.

Ao analisar isso ao longo dos anos, é possível identificar que houve anos com mais aprovados (272 em 2013) e menos aprovados (18 em 2006), o que indica a inconstância no número de vagas, uma vez que elas dependem da disponibilidade orçamentária e financeira do Estado.

Durante a análise foi identificado que a variável renda familiar estava alterada devido aos efeitos da inflação. Entretanto, os períodos definidos nas respostas se mantiveram constantes. Assim, eles foram agrupados, o que resultou em 08 níveis de renda.

Quanto ao ano de conclusão do ensino médio, os dados apresentaram muita variação entre si. Principalmente pelo fato de existir o fator limitante da idade como requisito de inscrição. Assim, foi elaborada nova variável que apurava o tempo de formação decorrido entre a ano do vestibular e o ano de conclusão do Ensino Médio.

Para facilitar a análise, foi elaborada a Erro! Fonte de referência não encontrada., por meio da qual podemos visualizar na primeira coluna as características avaliadas pelo questionário e que apresentam relevância para a análise proposta neste artigo. Na segunda coluna visualizam-se os dados gerais de todos os candidatos, e na terceira coluna os dados dos candidatos que foram aprovados. Nesta análise não foi adotada análise quantitativa, mas somente apontado o dado que apresenta maior percentual de respostas no período. Se houve alguma diferença na evolução dos anos, isso será apontado no campo de observação a parte.

Na Erro! Fonte de referência não encontrada. é possível identificar que os dados de idade, Estado civil, Estado de origem, raça, ensino médio, tempo de formação, decisão, motivação e principal influência não apresentaram diferenças entre os dois grupos.

Entretanto, algumas observações precisam ser realizadas. Apesar dos solteiros serem grande maioria dos aprovados, foi identificado aumento no número de casados, pois em 2005 eram 4,35\%, e em 2020 passou para 11\%.

Quanto à raça, para os candidatos, houve aumento no número de pardos, diminuição no número de brancos, e o número de candidatos negros se manteve constante ao longo do período.

Por outro lado, para os aprovados, houve aumento no número daqueles que se identificam como brancos e negros, acompanhado pela diminuição no 
número de pardos. Ou seja, possivelmente as cotas estão aumentando o número de negros, mas prejudicando o número de pardos.

Outra comparação interessante que surgiu dos dados é o fato de que grande parte dos candidatos trabalha em período integral, mas os aprovados são em sua maioria aqueles que não trabalhavam, portanto não contribuem para a renda familiar.

Com relação à renda familiar, os candidatos se consideram como renda média, mas no período foi identificado que os aprovados são aqueles que se encontram em uma faixa de renda menor. Além disso, houve um aumento de aprovados com renda baixa. 


\begin{tabular}{|c|c|c|c|}
\hline VARIAVEL & CANDIDATOS & APROVADOS & OBSERVAÇAO \\
\hline Idade & Mais de 23 anos & Mais de 23 anos & \\
\hline Estado civil & Solteiro & Solteiro & $\begin{array}{l}\text { No caso dos aprovados, houve aumento no } \\
\text { número de casados. }\end{array}$ \\
\hline Estado de Origem & Paraná & Paranä & $\begin{array}{l}\text { No caso dos aprovados, houve aumento de } \\
\text { aprovados de outros Estados. }\end{array}$ \\
\hline Local de origem & $\begin{array}{l}\text { Iinterior do } \\
\text { Paraná }\end{array}$ & Curitiba & \\
\hline $\mathrm{Rag} a$ & Branca & Branca & $\begin{array}{l}\text { Eim ambos os casos, houve aumento ino inúmero de } \\
\text { pardos e megros }\end{array}$ \\
\hline $\begin{array}{l}\text { Atividade Remunerada } \\
\text { Anterior }\end{array}$ & Periodo Integral & Nato trabalhava & \\
\hline Contribui Renda Familiar & Sim & NAO & \\
\hline Renda & Renda média & $\begin{array}{l}\text { Pouco abaixo da } \\
\text { renda media }\end{array}$ & $\begin{array}{l}\text { No caso dos aprovados, houve aumento no } \\
\text { número de aprovados em situagág de baixa renda. }\end{array}$ \\
\hline Ensino médio & Escola Pública & Escola Pública & $\begin{array}{l}\text { No caso dos aprovados, houve aumento no } \\
\text { numero de estudantes que cursaram o ensino } \\
\text { médio integrallmente em escola particular. }\end{array}$ \\
\hline $\begin{array}{l}\text { Tempo de formiaçâio do } \\
\text { EM }\end{array}$ & $\begin{array}{l}\text { Hä menos de } \\
05 \text { anos }\end{array}$ & $\begin{array}{l}\text { Há menos de } 0.5 \\
\text { anos }\end{array}$ & $\begin{array}{l}\text { No caso dos aprovados, houve aumento para } \\
\text { aqueles que concluíram o ensino médio há mais de } \\
\text { of anos. }\end{array}$ \\
\hline Turno de estudo & Todo noturno & Todo Diumng & \\
\hline Cursinho & Nấ fioz & $\begin{array}{l}\text { Por mais de um } \\
\text { ano }\end{array}$ & \\
\hline Participaçio no vestibular & Primeiro & $\begin{array}{l}\text { Segundo e terceiro } \\
\text { ano }\end{array}$ & \\
\hline Idiomas & NË le nenhum & Lê inglâs & \\
\hline Iniciou outing curso & $\begin{array}{l}\text { Vide } \\
\text { observagäo }\end{array}$ & 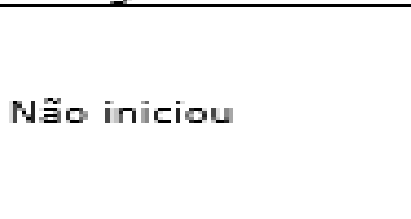 & 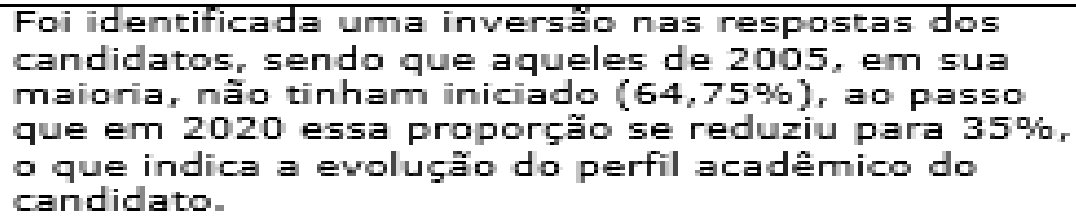 \\
\hline Decisấ quanto ao curso & $\begin{array}{l}\text { Absolutarmente } \\
\text { decidido }\end{array}$ & $\begin{array}{l}\text { Absolutamente } \\
\text { decidido }\end{array}$ & \\
\hline Motivagâo & $\begin{array}{l}\text { Contribuir para } \\
\text { a sociedade }\end{array}$ & $\begin{array}{l}\text { Contribuir para a } \\
\text { sociedade }\end{array}$ & \\
\hline Principal influência & Familia & Familia & \\
\hline
\end{tabular}

Fonte: os autores (2020). 
Por outro lado, quando se analisa o tipo de formação, tanto para candidatos, quanto para aprovados, é possível identificar a preponderância de escolas públicas, mas há uma tendência de alteração para aprovados formados integralmente em escola particular.

Já o tempo de formação indica candidatos e aprovados com menos de 05 anos de conclusão do Ensino Médio, apesar da tendência crescente daqueles que se formaram há mais tempo.

Com relação ao tipo de estudo preparatório, é possível identificar que a maioria dos candidatos fez o ensino médio integralmente noturno, e não fizeram cursinho, ao passo que para os aprovados, há uma inversão para aqueles que fizeram integralmente no noturno, e fizeram cursinho. Isso indica a necessidade de preparação para o concurso. Ainda mais quando se considera que enquanto a grande maioria dos candidatos está no primeiro vestibular, a maioria dos aprovados já está no mínimo no segundo ou terceiro concurso vestibular.

A questão dos idiomas é um pouco prejudicada por se tratar de uma questão recente, mas é possível visualizar que enquanto a maioria dos candidatos não lê outra língua, a maioria dos aprovados lê pelo menos em inglês.

Outro ponto de destaque é o tipo de formação acadêmica do candidato e do aprovado. No período, houve uma inversão com grande parte dos candidatos começando a apresentar nos anos recentes ter iniciado um curso superior. Apesar disso, a maioria dos aprovados nem iniciou o curso superior.

Ou seja, apesar de ter uma grande maioria que ao menos iniciou um curso superior, o processo seletivo tem selecionado aqueles que nem sequer iniciaram tal nível. Um dos motivos que pode estar acarretando isso é o requisito de ingresso que exige o ensino médio, e o concurso tem selecionado aqueles com conclusão há menos de cinco anos.

Do ponto de vista da gestão do conhecimento, existe um tipo de conhecimento aqui que poderia estar sendo agregado à organização, mas não tem sido adquirido pelo filtro do processo seletivo.

\section{Considerações finais}

Ao analisar o Curso de Formação de Oficiais, identifica-se que nas perspectivas aqui propostas há diferenças com o processo de formação das instituições de ensino superior tradicionais.

Se considerarmos que o processo de ensino é composto pelo aluno, professor, instituição e contexto, conforme definido por Miranda (2007), neste artigo podemos concluir que analisamos todas as perspectivas para análise do processo de formação do cadete.

Quanto à instituição, é possível concluir que o vínculo recente da instituição à UNESPAR mudou a forma como ela atua, principalmente com a implantação de disciplinas voltadas para a pesquisa acadêmica. 
Além disso, o currículo era determinado pelo Comandante da APMG, o que the concedia maior flexibilidade às contingências da Corporação, mas também não possuía uma linha de formação única dos Oficiais. Ou seja, aparentava focar na diversidade da formação de acordo com as demandas.

O currículo é voltado principalmente para as disciplinas policiais, com disciplinas de curta duração quando comparadas com disciplinas de outros cursos de graduação.

Na sequência, as cargas maiores de disciplinas ofertadas por ano são de Educação Física, elemento considerado basilar para a atividade policial dada necessidade de condição física para exercê-la. E também temos alta carga de disciplinas jurídicas, uma vez que a atividade policial toma por base o direito para as suas atividades.

Além disso, quando analisamos o processo de formação que conta com o suporte institucional de coordenadores e estrutura física dedicada, os mecanismos de Sensemaking (WEICK, 1995) e Sensegiving (GIOIA; CHITTIPEDDI, 1991) articulado por tais coordenadores atuam na formação para além da administração burocrática do curso.

Ao analisar o perfil dos instrutores identificamos que com a alteração dos currículos, os instrutores adaptam as suas aulas, e com isso incorporam novas experiências, e por resultado o cadete é formado baseado em práticas adotadas naquele momento na Corporação. Por outro lado, apesar da preferência pela experiência, os instrutores mais recentes apresentam graduação mais elevada de formação.

Por fim, a análise do perfil dos candidatos com a contraposição ao perfil dos aprovados permitiu identificar que existem alterações contextuais que não são trazidas tão somente pelo ensino em si, mas que os novos alunos estão alterando o seu perfil, e que inclusive chegou ao ponto de haver uma maioria com conhecimento disponível de curso superior, mas sendo filtrada pelos requisitos de ingresso do concurso ao CFO.

Como limitação desta pesquisa a falta de relatórios, ou informações mais antigas impede analisar os currículos antes da Constituição Federal de 1988 a qual demandou profundas alterações na atividade policial.

Para pesquisa futuras, recomenda-se aprofundar a análise coletando os planos de ensino, e possivelmente a análise de conteúdo possa ser a ferramenta adequada para avançar na análise. Sugere-se também a realização de entrevistas com instrutores, alunos e gestores da APMG para compreender melhor o processo de formação.

Do ponto de vista prático, observando o tamanho da carga horária do curso e considerando a complexidade da sociedade atual, talvez seja necessário alterar os requisitos de ingresso de ensino médio para ensino superior, como por exemplo, definindo como requisito do candidato possuir graduação em Direito. Isto permitiria alterar o currículo expandindo as disciplinas de formação policial, e em especial às disciplinas de pesquisas que aparentam se encontrar esmagadas e reduzidas. 


\section{REFERÊNCIAS}

APMG. Curso de Formação De Oficiais Policiais Militares. [S. I.], 2020. Disponível em: http://www.apmg.pr.gov.br/Pagina/Curso-de-Formacao-deOficiais-Policiais-Militares-CFO-PM. Acesso em: 13 set. 2020.

CRESWELL, John w. Projeto de Pesquisa: métodos qualitativo, quantitativo e misto. 2. ed. Porto Alegre: Artmed, 2007.

CUNLIFFE, Ann; COUPLAND, Chris. From hero to villain to hero: Making experience sensible through embodied narrative sensemaking. Human Relations, [s. I.], v. 65, n. 1, p. 63-88, 2012. Disponível em: https://doi.org/10.1177/0018726711424321

GIL, Antonio Carlos. Métodos e Técnicas de Pesquisa Social. 6. ed. São Paulo: Atlas, 2008.

GIOIA, Dennis A.; CHITTIPEDDI, Kumar. Sensemaking and sensegiving in strategic change initiation. Strategic Management Journal, [s. l.], v. 12, n. 6, p. 433-448, 1991. Disponível em: https://doi.org/10.1002/smj.4250120604

GOFFMAN, Erving. Manicômios, Prisões e Conventos. São Paulo: Persp, 1961.

MANNING, Peter K. Policing Contingencies. New York: University of Chicago Press, 2003. Disponível em:

https://doi.org/10.7208/chicago/9780226503523.001.0001

MANNING, Peter K. The Technology of Policing: Crime Mapping, Information Technology, and the Rationality of Crime Control. New York: New Yoork University Press, 2008.

MIRANDA, Eva. Ensino superior: novos conceitos em novos contextos. Tékhne - Revista de Estudos Politécnicos, [s. I.], v. V, n. 8, p. 161-182, 2007.

MORAIS, Lucilio Linhares Perdigão de; PAULA, Ana Paula Paes de. Identificação ou resistência? uma análise da constituição subjetiva do policial. Revista de Administração Contemporânea, [s. l.], v. 14, n. 4, p. 633-650, 2010. Disponível em: https://doi.org/10.1590/s1415-65552010000400005

PARANÁ. Lei de Promoção de Oficiais. [S. I.], 1969. Disponível em: https://www.legislacao.pr.gov.br/legislacao/pesquisarAto.do?action=exibir\&co $\mathrm{dAto}=11078$ \&indice $=1$ \& totalRegistros $=1 \& \mathrm{dt}=20.8 .2020 .11 \cdot 0.33 .947$. Acesso em: 11 set. 2020 .

PEREIRA BASILIO, Marcio. O Desafio da Formação do Policial Militar do Estado do Rio de Janeiro: Entre o Modelo Reativo e o Contingencial. Administración 
y Desarrollo, [s. I.], v. 38, n. 52, p. 71, 2010. Disponível em: https://doi.org/10.22431/25005227.156

RIBEIRO, Ludmila Mendonça Lopes; CRUZ, Marcus Vinicius Gonçalves da; BATITUCCI, Eduardo Cerqueira. Relação indivíduo e instituição total: socialização, controles e coesão internos em uma organização policial. Revista do Serviço Público, [s. l.], v. 56, n. 3, p. 295-308, 2005.

RIESSMAN, Catherine Kohler. Narrative Methods for the Human Sciences. CA, USA: Sage Publications, 2007.

ROSE, Diana. Análise de Imagens em Movimento. In: BAUER, Martin W; GASKELL, George (org.). Pesquisa Qualitativa com Texto, Imagem e Som. 13. ed. Petrópolis, RJ: Vozes, 2015.

SANTOS, Felipe Haleyson Ribeiro dos. A Construção da Identidade Profissional Policial-Militar Orientada pelas Lógicas Institucionais: Um Estudo de Caso no Estado do Paraná. 226 f. 2016. - Universidade Federal do Paraná, [s. l.], 2016. Disponível em: http://hdl.handle.net/1884/43092

STAKE, Robert E. A Arte da Investigação com Estudos de Caso. 2. ed. Lisboa: Fundação Calouste Gulbenkian, 2009.

VAN MAANEN, John. People processing: Strategies of organizational socialization. Organizational Dynamics, [s. l.], v. 7, n. 1, p. 19-36, 1978. Disponível em: https://doi.org/10.1016/0090-2616(78)90032-3

VÍDEO. Direção: TV Educativa. [S. l.: s. n.], 2006. Disponível em: https://www.facebook.com/anibal.neto.96/videos/746675015371442

WEICK, Karl E. Sensemaking in Organizations: Foundations for Organizational Science. Thousand Oaks: Sage Publications, 1995. 